\title{
Normative Media Research
}

\author{
Moving from the Ivory Tower to the Control Tower
}

\author{
Lars Nyre
}

\begin{abstract}
The article enquires about the role of researchers in an era of increasingly competitive innovation in the media industry. I argue that research-driven change in the mass media is possible, and that there should be more of it in the future. More democratic participation in mass media is the issue that most urgently needs to be resolved, and in Part II I will point out a possible strategy of reformation in the field. The article is a form of meta-theory or 'theory of science', and it zooms in on the normative attitude of the social researcher towards the larger society. The first part is a history of normativity in modern American and European social science from the 1920s onwards, with a focus on media studies. It sets the background for a framework for instructive media research, that is, research in which a normative goal is pursued with all the tools that social research can legitimately apply. I present three sectors of the media that can be directly and indirectly controlled by the researcher: the media's technical platforms, their editorial procedures, and citizens' participation in the media.
\end{abstract}

Keywords: media research, democracy, critical research, administrative research, instructive research

\section{Introduction}

The growing influence of 'new media' in social life coincides with the frenzy of innovation on the Internet and in mobile phone technology, and this development challenges the importance of old media like newspapers, radio and television. In the present article, I enquire about the role of media researchers in relation to this growth in new communicative practices.

Let me first remind you that the greatest sin of media researchers is to take the innovations at face value. "We specialise in undoing media hubris" Kaarle Nordenstreng (2007: 219) claims on behalf of media researchers. Most forms of communicative interaction were improved by electronic and digital means during the 20th century, but it is not obvious that the quality of communication has improved along with the means. Even though communication has become more efficient, it has not by implication become more democratic. There is a risk that innovations will actually stall societal progress, and thus new media developments should be vigorously investigated by researchers in order to reduce this risk. Investigating the role of researchers is a form of meta-theory or 'theory of science', and zooming in on social researchers' normative attitudes towards the larger society furthermore makes the present study a hermeneutical and political one. 
The most progressive way for researchers to approach the issue would be to design independent prototypes of new media alongside those of the commercial businesses, and to promote them systematically in public life. A writer as unlikely as Marshall McLuhan (1911-1980) recommended such an attitude. He said that the media researcher should move from the ivory tower to the control tower (Grossweiler 1998: 90), and thereby reiterated what Karl Marx famously said a hundred years before: "Philosophers have only interpreted the world differently, what matters is to change it" (Carver (ed.) 1991: 3). I agree with McLuhan and Marx that researchers should take control of at least some features of the media's social and political functions in order to improve them.

However, the tradition of progressive media research is weak in Nordic media studies, despite our shared social-democratic heritage since the 1940s, and our army of social engineers in fields like education, social services, healthcare, etc. Here I will formulate a theoretical rationale for an instructive attitude towards mass media and communication, and I am particularly interested in exploiting the potential for democratization in new media during the next 20-30 years.

The first part of the article is a history of normativity in modern American and European social science from the 1920 s onwards, with a focus on media studies. There are many epistemological rationales that limit the extent to which researchers should aid in the reformation of society, and I divide them into three traditions: social engineering, administrative research and critical research. I argue that they are all equally normative in their foundations.

The second part builds on these traditions to present a framework for instructive media research, that is, research in which a normative goal is pursued with all the tools that social research can legitimately apply. I will present three sectors of the media that can be directly and indirectly controlled by the researcher: the media's technical platforms, their editorial procedures, and citizens' participation in the media. As suggested above, more democratic participation in mass media is the issue that most urgently needs to be resolved, and in Part II I will point out a possible strategy of reformation in the field.

\section{Part I: A History of Normativity}

In social research, researchers carry a burden that can be called our normative anthropology, defined as a more or less conscious set of "ideas connected with some notion of a human good, end, purpose, or function (ergon)" (White 2003: 5). Researchers have a tendency to promote values in their capacity as researchers, because we do this in all other realms of life. Humans are subject to unwieldy processes such as emotional attachments, convictions and beliefs, and all researchers have a value orientation that will leave traces in their research projects, journal articles and monographs. Note that because this influence is unavoidable, it works even if the researcher is completely unaware of it.

Below I will discuss three research traditions ranging from the 1920 s to the present time, namely social engineering, administrative research and critical research. I will formulate their three different normative anthropologies, and clarify how they intend to use their values to influence society. While other classifications of media research are empirical (Jensen 2000; Carlsson 2007), mine is ideal typical. 


\section{Social Engineering from the 1900 s}

In the decades before World War I, people in the US were inspired by the progressive movement, where philosophers, philanthropists, industrialists and politicians believed that inequality and injustice could be alleviated by technological means. The progressive ideology was not communist or capitalist as much as rational and efficient. This political attitude has been crucial to many US presidents and their administrations. Starting in 1914, Woodrow Wilson's administration spent more money on industrial development than any earlier administration had done. In the late 1920s, Herbert Hoover reinvigorated spending on industrial development, and this was taken over by Franklin D. Roosevelt's New Deal in the 1930s and 1940s (Johnson 1997: 634ff).

Social engineering has a highly visible value orientation. It solved the problem of unavoidable influence by using influence like a politician or businessman would, albeit with the established methods of natural and social science. Progressive academicians took advantage of research methods to mould institutions and technologies in industrial states. In the political climate after World War II, university researchers played a crucial role in inventing and implementing new structures in society. With the state as the commissioner, researchers in Europe and the US aided great building projects, the controlled migration of large numbers of people, medical treatments, education reforms, and a great deal more. In the Nordic countries, the social-democratic reforms of the national Labour parties from the 1940s onwards were greatly influenced by the experimental approach to reforming society (Halvorsen and Stjernø 2008).

Andrew Feenberg (2006) reminds us that technocratic research projects of the mid$20^{\text {th }}$ century often failed miserably to improve conditions. Housing projects failed to improve living conditions for the inner-city poor, and reforms in psychiatry and health care introduced unforeseen problems that were in some cases worse than the initial situation. And indeed, the atomic bomb was created as a consequence of the large-scale concerted action of researchers.

There is a contemporary version of progressive research that can be called 'action research'. Although it is not widespread in Nordic media research, it merits discussion in the present context because of its clearly formulated normative anthropology. Action research is concerned with improving the situation of the people involved in the research project, for example by supporting re-education, equal participation and free choice (Argylis et al. 1985: 8-9). The purpose of a project is determined together with the people who would benefit from it if the hypotheses are good. The social mobilization towards "emancipatory action research" in certain university milieus is well described in Reason and Bradbury (2001) and Fals Borda (2001). Action research is normative in the sense that it is presumed that the end result, however grounded and open-minded the procedures are, will be better for you than your present conditions. It is justified by the idea of making people better persons, without requiring that everyone involved agrees or is even aware that his/her behaviour has improved. Owing to the learning process the participants go through, the research process itself may have political value. Chris Argylis says that "science in becoming experimental has itself become a mode of practical doing" (Argylis, p. 6).

The work of John Dewey (1859-1952) contains a classical rationale for this research approach. Dewey argues that we as humans always have a certain responsibility for our actions because they are intentional. It is easy to overlook this fact. "We rise in the 
morning, dress, eat, and go about our usual business without attaching moral significance to what we are doing" (Dewey 1908: 9). But where there is conduct, Dewey continues, "there is not simply a succession of disconnected acts but each thing done carries forward an underlying tendency and intent" (Dewey 1908: 11). He argues that these seemingly neutral actions have moral implications, and demands that people learn about the consequences of their actions, and let this knowledge guide their behaviour.

The primary objective of Dewey's research ideology is the facilitation of enjoyments, or the pursuit of happiness in line with the American constitution. This denotes human well-being in the broadest social, economic and political sense. In Dewey's view, enjoyments that issue from intelligent conduct are particularly valuable, and should be cultivated in social life. Knowledge about the political workings of society is supreme among these intellectual enjoyments.

The more connections and interactions we ascertain, the more we know the object in question. Thinking is search for these connections. Heat experienced as a consequence of directed operations has a meaning quite different from the heat that is casually experienced without knowledge of how it came about. The same is true of enjoyments. Enjoyments that issue from conduct directed by insight into relations have a meaning and a validity due to the way in which they are experienced. Such enjoyments are not repented of; they generate no aftertaste of bitterness. Even in the midst of direct enjoyments, there is a sense of validity, of authorization, which intensifies the enjoyment (Dewey 1994: 154).

Dewey wanted to use scientific methods to increase the number of such intelligent enjoyments. He would not have been content to study behaviour a posteriori as most academicians would. He recommended experimental methods, where research instruments are trained on a specific dimension of social reality to find out how it functions, and to find out whether the newly acquired knowledge can influence its functions in the future.

Dewey wanted to discover social mechanisms and predict the consequences of various forms of social action. "Experimental empiricism in the field of ideas of good and bad is demanded to meet the conditions of the present situation", he stated programmatically (Dewey 1994: 149). This is a progressive statement. Dewey wanted the researcher to make prescriptions for behaviour, and potentially build restrictions into a technological or social system so that they encourage only some types of behaviour. Dewey argues that the social scientist's true purpose (ergon) is to facilitate the kind of actions that lead to good consequences in society. The pursuit must necessarily take the form of social experimentation and attempts at political reform. Remember that Dewey reflected on this method in the early $20^{\text {th }}$ century, before the moral failures of social engineering and technocracy had become evident.

And indeed, there are several problems with the position that Dewey and the later progressive researchers championed. John Durham Peters rejects the progressive ideology as simply naive. They are "old democrats who have a touchingly virginal faith in the goodness and intelligence of the people" (Peters 2003: 224). This criticism is cynical if Durham Peters means to suggest that there is no goodness and intelligence among people, but quite reasonable if he means that researchers may not be able to engage it in the pursuit of their goals. Another prominent critic, James Carey, is sceptical of this kind of interventionist research, and refers to its practitioners as "the new priesthood" (Carey 
1989: 94). He does not trust their moral stature to be as solid, or their pragmatic insight into society to be as deep, as the scope of their plans for social change may suggest.

The dilemma involved in Dewey's position is that in order to promote good consequences, you have to define which types of behaviour are good, and exclude a host of other forms of behaviour because they are bad, or at least not good enough. How do you choose which is which? Let us say that you were actually able to determine the criteria for good behaviour. Still there is a problem in that you may lack the motivation to keep on believing that your position is best, and you may lose faith in it before the project is completed. And if you actually manage to defend and promote it with full force throughout, haven't you then entered the field of politics or even religion, so that in effect you have stopped being a researcher?

There is a further problem with Dewey's instructive orientation. Let us say that you have not only managed to keep up your faith in a certain solution, but that you have even completed a wonderful media research project that promoted the preferred changes successfully. What if another researcher copies your methodology, which must have been very efficient, and tries to set in motion a completely different set of changes in another context? It may turn out that what you created was only an empty procedure for changing media behaviour, equally applicable to neo-fascism or the radical left. If your method can inspire any kind of change, then your progressive endeavour has failed.

\section{Administrative Research from the 1940 s}

Other research traditions choose a safer approach to social change than the progressives did. The label "administrative research" was first attached to Paul Lazarsfeld and his research group at Columbia University in the 1940s, and has become a rather vague term referring to research justified by the values of an existing institution in society, whether it is a media company, a non-governmental organization, a state department or a local community. Administrative research is typically guided by the normative anthropology of the institution and not the researcher, and there is typically a low intensity of ethical engagement at the research end.

Statistical media research is a good example of administrative research. Researchers compile audience figures for a television station, with a demographic breakdown and changes in figures over time. This may involve facts and figures about institutions like Danmarks Radio or Sveriges Television, and the policies, economics and organizational structures of public service broadcasting. The individual person is made very small in this approach. If you are interviewing 2,400 people in a quantitative survey, you must follow procedure, and you cannot be concerned with the well-being of the each individual. Statistics necessarily removes the depth of character of persons by cataloguing social facts about them.

Administrative research tends to be conservative in the sense that the facts and figures indirectly support the institutions in question, and very often do not relate to alternatives or faults with the existing ones. In practice, such research is often simply a means of administrating the status quo by making the norms of dominating agents of influence, like the state bureaucracy and big business, more acceptable to the public. The European Union funds a huge body of administrative research, for example COST A20 "The Impact of the Internet on Mass Media in Europe" (2001-2006). Reports are filled 
with statistical information and analyses of selected media, as formally agreed on in a memorandum of understanding between researchers and the EU. The most commercial version of administrative research could be called assigned research. Semi-academic companies do research on behalf of, for example, telecom companies, without any ethical requirements of their own.

Regarding the normative rationale, administrative research is associated with the position called 'ethical neutrality'. You can achieve neutral scientific results in social research, provided you distinguish between the spheres of research and conviction. Theorists believe that the value orientation (which results from conviction) can be counteracted through objectifying procedures.

Julien Freund (1921-1993) considered that the societal influence of the social sciences had been proven beyond a reasonable doubt, and he was concerned to curtail it. Freund's approach is that of a classical 'ethical neutralist'. He conceives of researchers as moral and political beings with an independent opinion of what is right and wrong in society. He conceives of personal conviction as essential for wanting to be educated, and wanting to learn about society through research projects. Freund particularly emphasizes the influence of conviction on the researcher's selection processes. Only within a value-driven decision-making process can the scientist or scholar apply the procedures of scientific investigation, which consist of "accurate observation, criticism of texts, surveys and documents, determination of causal relationships, comparison, etc." (Freund 1966: 53).

The influence of the value orientation on research procedures is alarmingly great, according to Freund. Almost all intellectual processes involved in justification, discovery and documentation are driven by the value orientation. For example, it "determines the selection of the subject of study, i.e. it enables us to detach a definite object from reality, which itself is diffuse" and "once the topic has been chosen, it guides us in sifting the essential from the secondary, i.e., it defines the historical individuality or uniqueness of the problem in effecting a choice from any infinitude of details, elements and documents" (Freund 1966: 55-56).

Still, the value orientation must be neutralized. Freund points a warning finger at social engineers and other researchers who are explicitly change-oriented or political in their work: "His task is to interpret, to analyze, to describe a situation, using all the resources of the scientific method, but not to contribute his own views or to call one opinion right and another wrong". Freund presents a moral imperative for social research: "Science may deal with evaluations, provided that it does not evaluate them" (Freund 1966: 84). According to the position of ethical neutrality, the sociologist will cease doing scientific work the moment he himself expresses an opinion on those opinions. It is consequently very important to distinguish between the spheres of research and conviction. The researcher is simply not allowed to promote his convictions in the way that social engineering presumes.

For the sake of his personal dignity, if for nothing else, the professor should concentrate on the teaching required of him, instead of playing the cultural reformer without the practical means of carrying out reforms, or parading the qualities of a statesman while lacking that basic requirement, a state to organize (Freund 1966: 80-81). 
Academic research must have a strictly limited mandate in order to counteract the temptation for cultural reform. It goes against the grain of research to postulate future action, and this is a requirement with serious repercussions for the political thrust of research. "The sociologist, just as much as the historian, is faced with a completed action or a given behavior, and must a posteriori explain its causes and motives, seek to understand its purpose and analyze the means used to attain it" (Freund 1966: 77). This strategy is supposed to effectively remove research from the sphere of conviction, and is in this sense starkly different from social engineering and critical research.

In my view, there are several problems associated with the position that Freund champions. The gravest problem is the attempt to make research on future situations illegitimate in the research community at large. In one sense this mentality actually involves a ban on thinking about the future, as the future lends itself easily to thoughts about how it should ideally be. This makes the whole notion of ethical neutrality sound rather unrealistic.

The second problem with Freund's requirements for research is that the constant influence it has on society is underestimated. Freund seems to presume that those who actively neutralize their value orientation and only "deal with evaluations, provided [he] does not evaluate them" (Freund 1966: 84) have consequently no influence on society and its politics. But this is certainly not the case. Researchers communicate a value orientation also when they contribute "neutrally" to the empirical understanding of a social practice, because the public's knowledge of an already dominant behaviour is expanded instead of being refocused on something different. Researchers, however, may not be felt to be normative in their time, and they may not themselves appreciate the conservative influence they exert on others.

A third problem is the pretence of neutrality that researchers sometimes adopt. For example, it may be opportune for the researcher to under-communicate controversial findings that might make the project appear politically incorrect, and in some cases researchers may feel uncomfortable if their findings are too politically correct. For both these reasons, there is a risk that researchers will present their results in cowardly or downright dishonest ways. Indeed, researchers who have explicit political agendas may sometimes be considered more honest than those who appeal to the court of ethical neutrality without convincing the readers that they actually believe neutrality is possible (Nyre 2005).

\section{Critical Research from the 1960s}

While administrative research tries to be as neutral as possible, critical research tries to be as partisan as possible. The label "critical research" was introduced with the socialist theory of the Frankfurt school after World War II, but gained widespread political momentum from 1968 onwards. Critical research is found, for example, in British cultural studies, feminism and multiculturally oriented social research. It typically has a clearly formulated value orientation that the researcher has formulated him-/herself, and therefore there is always a notable intensity of ethical engagement.

Critical researchers are driven by an intuitive sense of what is morally right and wrong. If you are happy about the current state of things, you will never become a critical media researcher. Critical media researchers wish to form alliances with ordinary people, who they think should be allowed greater freedom and not be so profoundly manipu- 
lated by media businesses. This alliance with citizens has a long tradition, for example among writers such as Bertolt Brecht (1932), Hans Magnus Enzensberger (1969) and Murdock (2005). The injustice and inequality in society motivate you to portion out the blame, and these moral indignations are typically quite personal and based on first-hand experience. Finlayson (2005: 84 ) points out that a moral obligation always addresses us in the first person. In a more methodological vein, political theorist Will Kymlicka states that all political theories are based on intuitions, for example the intuition that slavery is unjust. This is what drives political reasoning at the practical and theoretical level. "If a theory of justice matches our considered intuitions, and structures them so as to bring out their internal logic, then we have a powerful argument in favour of that theory" (Kymlicka 2002: 6).

There is a version of critical research that can be called dystopian. The dystopian version presumes that there is really no hope of improvement, because the commercial and political structures of society are already too rigid. Dystopian researchers are sensitive to what they conceive of as abuse of power by the dominant forces in society, and they protest this abuse forcefully in their work. Their criticisms are formulated in an analytic way, most often based on hermeneutic research methods (rhetorical analysis, text analysis, reception studies and historical studies). This attitude was easily adapted to the media industry and its popular cultures, relating for example to systematic inequality of political representation and information gaps favouring groups with great resources.

Although this dystopic anthropology is indeed rooted in visions of good future solutions, there is often a strange lack of interest in describing courses of action that would lead to the desired future. This attitude is enthusiastically dystopian in a way that makes attempts at intervention seem fruitless. Nevertheless, there is an impetus for change in the desperation itself, and it can be contagious, fuelling the critical energies of the reader. Writers like Noam Chomsky and Naomi Klein have succeeded well using this rhetorical strategy. But the problem is that these researchers are not good at presenting credible alternatives to what they criticize, and it is highly unusual for them to try to build real alternatives with experimental methods, like a social engineer would do. It seems that the energetic formulation of negative criticism has worn them out.

Half a century after the emergence of critical media research, a liberal, postmodern form of "compassionate research" dominates the field. Researchers care very much about the personal satisfaction of individuals and subgroups in relation to their media consumption. There is a good example of this approach in Rodman and Vanderdonckt (2006), where the researchers are in alliance with music lovers, and are clearly also music lovers themselves. They analyse the business strategies of multinational record companies based on descriptions of music consumption in their own lives, and they indignantly criticize these multinationals for making people suffer their aggressive and unjust sanctions on musical culture. This intuitive alliance with interest groups or communities or ethnic minorities or multicultural groups creates research of very specific social value, but with little interest for people outside the group in question.

When it appears that ordinary people cannot be fooled or tricked, or simply be wrong about things, the alliance with the citizen has gone too far. The psychological reward for taking such a socially responsible position is that you will come across as a humanitarian, philanthropic researcher. You can live comfortably with the image of being naive because your motivation is so good. 
However, just as there is something to learn from the objectivity of the administrative attitude, there is also something to learn from the intuitive humanitarianism of critical research. In the $2000 \mathrm{~s}$, the mass media are structures of a magnitude that can hardly even be imagined by researchers, and there is reason to suspect that dominant organizations and businesses are not really interested in promoting democratic values. Critical research scrutinizes the morality of the fourth estate (which scrutinizes the government, parliament and the courts), and it strives to keep the mass media from gaining hegemonic power over the public sphere. Therefore such research is indispensable to any democratic state.

\section{Part II: The Instructive Attitude}

The subtitle of this article promises to relocate the researcher from the ivory tower to the control tower. The history of normativity makes it clear that researches have values and opinions about society whatever we do. We maintain dominant institutions, we form alliances with groups of citizens, and we inspire actions that will have good consequences for society. Media researchers have an influence on society just like business people, state bureaucrats and politicians do, but while media researchers typically try to neutralize their influence to protect the legitimacy of their research, the latter are free to use their influence without feeling awkward or guilty. In the second part, I will argue that we have a moral duty to use our knowledge in an attempt to improve public communication.

Stating that researchers should enter the control room is tantamount to saying that they should become active partners in the frenzy of innovation in the mass media. I have suggested that the most pressing issue is to democratize the new media to compensate for old failures. To get started, the researcher must find out what sectors of the media need to be controlled, and which of them he can reasonably expect to be able to control. As stated above, I will point to technical platforms, editorial procedures and citizen participation as the crucial sectors in this regard. Three writers are symbolically important in my argument, namely Marshall McLuhan, Jürgen Habermas and John Dewey, respectively. Here I quote them as authorities in the formulation of an ideal typical research strategy for media studies. More modest and empirically grounded approaches to the same topics can be found in Nyre (2007) and Nyre and Ala-Fossi (2008).

\section{Technical Platforms}

One of the sectors that media researchers can influence is the design of new platforms and interfaces. Like commercial innovators, researchers can test various set-ups of the technology, and see how participants react in terms of communicative qualities. Preferably, researchers should be able to build such platforms on campus, and experiment with them along with students and ordinary citizens. By shaping technologies in this way, the researcher can aid in the construction of good consequences, like Dewey requires.

My purpose is to strengthen the legitimacy of technical experimentation among media researchers by connecting Dewey's pragmatism with Marshall McLuhan's media philosophy. McLuhan focussed on the ways in which electronic media work on our senses. He was among the first to think of the mass media as human environments in a sensory 
and technological sense. McLuhan's theories have a pronounced, some would say coarse, materialism. He says that "technological media are staples or natural resources, exactly as are coal and cotton and oil" (McLuhan 1994: 21). The media are physical entities that people are involved with perceptually every day, arranging their habits and preferences around them. "Any technology tends to create a new human environment", McLuhan claims. "Technological environments are not merely passive containers of people but are active processes that reshape people and other technologies alike" (McLuhan 1962: i). The mass media are so central to our everyday lives that it would be irresponsible not to include them among the basic practices of society, on a par with the right to vote, the school system and electrical infrastructures.

McLuhan postulated that the message of the medium is its long-term effects on perception, polemically adding that the present politically and socially relevant content is of minor importance. McLuhan boldly formulates a law about the relationship between technology and communication.

For the "message" of any medium or technology is the change of scale or pace or pattern that it introduces into human affairs. The railway did not introduce movement or transportation or wheel or road into human society, but it accelerated and enlarged the scale of previous human functions, creating totally new kinds of cities and new kinds of work and leisure (1994: 8).

A medium's core characteristic is that it changes the ratio of the senses used in the effort to communicate compared to the previous ratio among members of a society. After becoming a prominent means of communication, it promotes and cultivates some perceptual activities more than others, and in this indirect way it causes social change. Methodologically, his conceptual probes into the experiential qualities of such environments are of continuing importance (see Bolter and Grusin 1999).

The quote above should not be rejected too hastily as deterministic. With some refinement, McLuhan's law becomes a useful analytic tool, and indeed, Moore's law, which says that the processing power of computer chips will double every eighteen months (Rifkin 2000: 20), can be interpreted as a quantitative specification of McLuhan's law in the domain of the computer. Nyre (2008b) contains a systematic historical application of McLuhan's law to the sound media (telephone, radio, music recording).

Let me take the pattern of distribution in analogue broadcasting as an example of the democratic impact of technologies. Traditional radio and television have at least two technical features that are beneficial for democratic purposes: non-rivalry, in that consumption does not reduce the availability for others, and non-excludability, in that all citizens can receive the signal equally (Moe 2008: 25ff). These features have traditionally been used to create universal access to programmes for all citizens, and it creates a type of public sphere that is in principle shared by all. While the relationship between procedures and viewers feels quite personal, it is facilitated by an electronic infrastructure common to millions of people all over the world. This type of communication has been called 'para-social interaction' by Horton and Wohl (1956), "for anyone as someone-structures" by Paddy Scannell (2000), and also "secondary orality" by Walter Ong (1982), and it will continue to be of great importance for democracy. Nevertheless, non-rivalry and non-excludability are slowly losing momentum with the introduction of pay-per-view services and password-protected access, and what McLuhan calls a 
'change in scale or pace or pattern' is clearly at work.

New technology can jolt the prevailing regimes of communication for good and for worse. The medium's behavioural restrictions are taught, conserved and translated within the technological system, and will die out if the technologies are removed or their everyday functions are taken over by newer solutions. A mass medium can be thought of as an expressive arena in which specific techniques of communication are created and kept active by a process of 'naturalization'. To say that an interface is embodied means that the user's perceptual skills are cultivated in one direction that becomes natural at the cost of potential qualities in other directions. The instructive researcher will create good consequences by replacing technologies, and the process of replacement can go on indefinitely.

\section{Editorial Procedures}

A second sector that researchers can and must influence is the organization of editorial work among journalists and other media employees. Think of the specific requirements of producing a news bulletin, compared with a phone-in programme, a documentary or a soap opera. Researchers' knowledge of editorial procedures must be well developed if they are to launch an experiment with democratization. Democracy relies heavily on predictability, in the form of stable procedures that allow everybody to know in advance what they will be participating in, and what the formal consequences of their actions will be. It is also important that they have equal opportunity to prepare for a performance. Researchers must make sure that this equality of access for all citizens is accomplished at the editorial level.

Jürgen Habermas is famously concerned with the norms and procedures of ethical communication. He presumes that communication can change opinions, preferences and interests among citizens (Knapskog, p. 114; Calhoun 1992), and claims that speech has a special position in the public sphere. The lifeworld as a whole, and therefore also the public sphere, requires only "mastery of a natural language", as "it is tailored to the general comprehensibility of everyday communicative practice" (Habermas 1996: 360). Habermas says that the crucial role of the public sphere is to be "a sounding board for problems that must be processed by the political system because they cannot be solved elsewhere. To this extent, the public sphere is a warning system with sensors that, though unspecialized, are sensitive throughout society" (Habermas 1996: 359).

What basic procedures should a democratic medium have to be sensitive throughout society? A strong formulation of the procedural scheme can be found already in Structural Transformation (1962), where Habermas lets sociologist C. Wright Mills define the ideal public sphere on his behalf.

In a public, as we may understand the term, (1) virtually as many people express opinions as receive them. (2) Public communications are so organized that there is a chance immediately and effectively to answer back any opinion expressed in public. Opinion formed by such discussion (3) readily finds an outlet in effective action, even against - if necessary - the prevailing system of authority. And (4) authoritative institutions do not penetrate the public, which is thus more or less autonomous in its operation (C. Wright Mills, quoted in Habermas 1990: 358). 
Interestingly, Habermas recommended this definition of the public because he found it particularly suitable for empirical investigations (Habermas 1990: 358). The first point on the list is problematic, as it would be impossible to accomplish a 50/50 share of speakers and listeners in states with 50-100 million inhabitants.

The second to fourth points on the list are more realistic, although highly demanding even for the most advanced Western democracies. But do people have the chance to immediately and effectively respond to opinions expressed in public? It seems clear that journalists as a profession control the choice of topics and speakers on the air, and therefore decide who can effectively answer back. The media's agenda setting has become a new type of power, which makes it impossible to think of the mass media as open-ended public spheres. Politicians and editors alike ought to more forcefully acknowledge the value of critical strategies of interpretation by audiences, Habermas suggests. But market strategies predominate, so that information is always mixed with entertainment, and the content is arranged episodically with complex relationships broken down into smaller pieces. The mass media as they function now have introduced a syndrome of depolitization of audiences, Habermas says (1996: 377).

Habermas implies that the media have themselves become authoritative institutions, so that instead of cultivating good communication in the public sphere they hamper it. Following his lead, one might fear that the procedures and patterns of behaviour are so locked into the platforms and interfaces of mass media that they have become unchangeable. A dose of brutal realism is required here. Langdon Winner argues that the designs and arrangements of industrial artefacts are similar to legislative acts or political foundations in establishing frameworks for public order that will endure over many generations. "Because choices tend to become strongly fixed in material equipment, economic investment, and social habit, the original flexibility vanishes for all practical purposes once the initial commitments are made" (Winner 1986: 29). The work of Jacques Ellul (1964) and Albert Borgmann (1984) represents similar critical perspectives on technology.

If we go along with this argument, it follows that it will be very difficult to change the mass media's authoritative and undesirable procedures. But regardless of the sobering nature of Winner's argument, it opens up a reconstructive potential that Habermas doesn't see. The problem is that Habermas isn't constructively concerned with technology, and he fails to investigate exactly how public deliberation is affected by the various platforms it appears on. If media technology is not considered a central arena of the struggle for power and influence, then the potential for change in the mass media will be thrown out with the bathwater.

\section{Citizen Participation}

The researcher can control features of the technical platforms and the organization of editorial procedures. But this control would lead nowhere without greatly increase public participation by ordinary citizens. The third sector that the researcher can and must influence is people's willingness to participate in alternative procedures of communication on alternative platforms, and this must be done by forming alliances with various groups of citizens. Democracy cannot work properly without grassroots participation. Researchers can influence civil society organizations, activists, protesters and grassroots 
movements. The rationale for such alliance-building can be found in writers as diverse as Henry Jenkins (2006), Coleman and Gøtze (2001) and Peter Dahlgren (2005).

The philosopher John Dewey has something symbolically important to say. He was deeply concerned about the condition of the public sphere in modern democracies, and felt that the mass media are pushing people apart instead of pulling them together. He said: "There is too much public, a public too diffused and scattered and too intricate in composition. And there are too many publics, [...] with little to hold [them] together in an integrated whole" (Dewey 1991: 137). Procedures in which the masses do not have the chance to inform the experts of their needs will become an "oligarchy managed in the interest of the few" (1991: 208). Dewey wants to experiment with more communitybuilding in public spheres. "The man who wears the shoe knows best that it pinches and where it pinches, even if the expert shoemaker is the best judge of how the trouble is to be remedied" (1991: 207).

Being a politically conscious person implies a reflexive consciousness about goals and values, and this Dewey calls intelligence. He uses the term in a moral and not psychological way. Intelligence is "conduct in which the individual thinks and judges for himself, considers whether a purpose is good or right, decides and chooses, and does not accept the standards of his group without reflection" (Dewey 1908, x). In order to be a responsible citizen, you must be willing and able to address the interests of your community in public, with the means at your disposal.

The most immediate means at citizens' disposal is verbal language, and it is a crucial task for media researchers to cultivate it among students and promote it in public. Interestingly, Dewey, just like Habermas, promotes live speech. "The winged words of conversation in immediate intercourse have a vital import lacking in the fixed and frozen words of written speech" (Dewey 1991, 218). Speech can help laypersons and social groups reconcile themselves more intelligently to each other, and do so in public arenas with relative ease. The alliance with citizens must be established with both qualitative and quantitative methods, and must feed into the construction of prototypes and editorial procedures.

\section{Conclusion}

Research-driven change in the mass media is possible, and there should be more of it. In the introduction, I stated that we may not have improved the quality of communication just because we have invented electronic arenas such as television and the Internet. Communication may have become more efficient, but it may not have become more democratic, and the main reason for media researchers to enter the control room is to change the media in this regard.

My argument is quite optimistic with respect to researchers' ethical engagement, theoretical rationale and empirical opportunity to effect change in society. But in closing, I will point out a dilemma inherent in all attempts at change and improvement. Even if researchers operate from a concerted plan for how to change the technical platforms and editorial procedures and how to inspire citizen participation, we cannot know in advance that the result will be good. The sluggishness of the social world will lead to a brutal falsification of theories, and enforced reorientation of value orientations. Researchers must acknowledge that if it doesn't work, it doesn't work, and then we must orient our attempts at improvement towards other, more promising facts on the ground. 
A reflexive researcher knows that failure to change the media is a more-than-likely outcome. Fortunately, a research article that explains why a platform and a set of procedures should be abandoned is just as valuable as one that explains why they are a great success. In both cases, a step has been taken in the direction of improvement.

\section{Literature}

Argylis, Chris, Robert Putnam and Diana McLain Smith (1985) Action Science. Concepts, Methods and Skills for Research and Intervention. San Francisco: Jossey-Bass Publishers.

Borgmann, Albert (1984) Technology and the Character of Contemporary Life. Chicago: Chicago University Press.

Bolter, J. David and Richard Grusin (1999) Remediation. Understanding New Media. Cambridge, MA: MIT Press.

Brecht, Berthold [1932] (2001) 'The Radio as a Communications Apparatus', in Silberman, Marc (ed.) Brecht on Film and Radio. London: Methuen.

Calhoun, Craig (1992) 'Introduction: Habermas and the Public Sphere', in Calhoun, Craig (ed.) Habermas and the Public Sphere. Cambridge (US): MIT Press.

Carey, James (1989) Communication as Culture. Essays on Media and Society. New York: Routledge.

Carlsson, Ulla (2007) 'Media and Mass Communication Research Past, Present and Future. Reflections from a Nordic Horizon', Nordicom Review, Jubilee Issue 2007, pp. 223-229.

Carver, Terrell (ed.) (1991) The Cambridge Companion to Marx. Cambridge: Cambridge University Press.

Coleman, Stephen and John Gøtze (2001) Bowling Together. Online Public Engagement in Policy Deliberation. London: Hansard Society.

Dahlgren, P. (2005) 'The Internet, Public Spheres, and Political Communication: Dispersion and Deliberation', Political Communication, 22, 147-162.

Dewey, John (1908) Theory of the Moral Life. New York: Holt, Rinehart and Winston.

Dewey, John (1994) The Moral Writings of John Dewey. Edited by James Gouinlock. Amherst: Prometheus Books.

Dewey, John (1991) [1927] The Public and its Problems. Athens: Swallow Press.

Ellul, Jacques (1964) The Technological Society. New York: Vintage Books. Translated from the French by John Wilkinson.

Entzensberger, Hans Magnus [1970] (2000) 'Constituents of a Theory of the Media', in John T. Caldwell (ed.) (2000) Theories of the New Media. London: Athlone Press.

Fals Borda, Orlando (2001) 'Participatory (action) Research in Social Theory. Origins and Challenges', in Reason, Peter and Hilary Bradbury (eds.) Handbook of Action Research. Participative Inquiry and Practice. London: Sage.

Feenberg, Andrew (1999) Questioning Technology. New York: Routledge.

Feenberg, Andrew (2006) 'Pragmatism and Critical Theory of Technology', unpublished manuscript.

Finlayson, James G. (2005) Habermas. A Very Short Introduction. Oxford: Oxford University Press.

Freund, Julien (1966) The Sociology of Max Weber. London: Penguin.

Grossweiler, Paul (1998) Method is the Message. Rethinking McLuhan Through Critical Theory. Montreal: Rose Books.

Habermas, Jürgen (1990 [1962] Strukturwandel der Öffentlichkeit. Untersuchungen zu einer Kategorie der bürgerlichen Gesellschaft. Frankfurt: Suhrkamp.

Habermas, Jürgen (1996) Between Facts and Norms. Cambridge: Polity Press.

Halvorsen, Knut and Stjernø, Steinar (2008) Work, Oil and Welfare. The Welfare State in Norway. Oslo: Universitetsforlaget.

Horton, Donald and Wohl, Richard [1956] (1979) 'Mass Communication and Para-Social Interaction: Observations on Intimacy at a Distance', in Gumpert, Gary and Cathcart, Robert (eds.) INTER/MEDIA. Interpersonal Communication in a Media World. New York: Oxford University Press.

Innis, Harold [1951] (1991) The Bias of Communication. Toronto: University of Toronto Press.

Jenkins, Henry (2006) Convergence Culture. Where Old and New Media Collide. New York: New York University Press.

Jensen, Klaus Bruhn (2000) 'On the Edge A Meta-Analysis of the State of Media and Communication Research', Nordicom Review 2/2000, pp. 23-30.

Johnson, Paul (1997) A History of the American People. London: Harper Perennial.

Knapskog, Karl (2001) 'Journalistikk og deliberativt demokrati' [Journalism and deliberative democracy], in Eide, Martin (ed.) Til Dagsorden!. Oslo: Gyldendal Akademisk. 
Kymlicka, Will (2002) Contemporary Political Philosophy. Oxford: Oxford University Press.

McLuhan, Marshall [1962] The Gutenberg Galaxy.

McLuhan, Marshall (1994) [1964] Understanding Media. The Extensions of Man. Cambridge: MIT Press.

Moe, H. (2008) Public Broadcasters, the Internet and Democracy: Comparing Policy and Exploring Public Service Media Online. Manuscript for PhD-dissertation. University of Bergen.

Murdock, Graham (2005) 'Building the Digital Commons. Public Broadcasting in the Age of the Internet', in Greg Lowe and Per Jauert (eds.) Cultural Dilemmas in Public Service Broadcasting. RIPE@2005. Göteborg: Nordicom.

Nordenstreng, Kaarle (2007) 'Discipline or Field? Soul-searching in Communication Research', Nordicom Review, Jubilee Issue 2007, pp. 211-222.

Nyre, Lars (2005) ‘Apologetic Media Research’, Nordicom Review 27(1): 97-99.

Nyre, Lars (2007) 'Minimum Journalism. Experimental Procedures for Democratic Participation in Sound Media', Journalism Studies (8)3: 397-413.

Nyre, Lars (2008) Sound Media. From Live Journalism to Music Recording. London: Routledge.

Nyre, Lars and Ala-Fossi, Marko (2008) 'The Next Generation Platform. Comparing Audience Registration and Participation in Digital Sound Media', The Journal of Radio and Audio Media. (15)1: 1-18.

Ong, Walter (1982) Orality \& Literacy. The Technologizing of the Word. New York: Routledge.

O'Sullivan, Sara (2005) 'The Whole Nation is Listening to You': the Presentation of the Self on a Tabloid Talk Radio Show', Media, Culture and Society vol. 27(5): 719-738.

Peters, John Durham (2003) 'Retroactive Enrichment: Raymond Williams's 'Culture and Society', in Katz, Elihu et.al. (eds.) Canonic Texts in Media Research. Cambridge (UK): Polity Press.

Reason, Peter and Hilary Bradbury (eds) (2001) Handbook of Action Research. London: Sage.

Rifkin, Jeremy (2000) The Age of Access. New York: Tarcher/Putnam.

Ross, Karen (2004) 'Political Talk Radio and Democratic Participation: Caller Perspectives on Election Call', Media, Culture and Society vol. 26(6): 785-801.

Rodman, Gilbert and Cheyanne Vanderdonckt (2006) 'Music for Nothing or, I Want My mp3. The Regulation and Recirculation of Affect', Cultural Studies 20(2-3): 245-261.

Scannell, Paddy (2000) 'For Anyone as Someone Structures', Media, Culture \& Society, nr. 1/2000. London: Sage.

White, Michael (2003) Political Philosophy. An Historical Introduction. Oxford: Oneworld.

Winner, Langdon (1986) 'Do Artifacts Have Politics?' in The Whale and the Reactor: A Search for Limits in the Age of High Technology. Chicago: University of Chicago Press.

LARS NYRE, Dr.Art., Associate Professor, Department of Information Science and Media Studies, University of Bergen, Norway, lars.nyre@infomedia.uib.no 